\title{
Novel application for pseudopodia proteomics using excimer laser ablation and two-dimensional difference gel electrophoresis
}

\author{
Akihiko Ito ${ }^{1,2,7}$, Takahiro Mimae ${ }^{2,3,7}$, Ying-Shan-Zhu Yamamoto ${ }^{4}$, Man Hagiyama ${ }^{1,2}$, Jun Nakanishi ${ }^{5}$, \\ Masaoki Ito ${ }^{3}$, Yoichiroh Hosokawa ${ }^{6}$, Morihito Okada ${ }^{3}$, Yoshinori Murakami ${ }^{2}$ and Tadashi Kondo ${ }^{4}$
}

We developed a novel application to conduct pseudopodia proteomics. Pseudopodia are ventral actin-rich protrusions and play functional roles in cell migrations. Identification of pseudopodia proteins leads to a further understanding of malignant phenotypes of tumor cells and novel therapeutic strategies. In our application, tumor cells were placed on a fibronectin-coated porous membrane to form pseudopodia. According to the motile potentials of the cells, the cells formed pseudopodial microprocesses in the pores. An excimer laser, which was used for ophthalmic refractive surgeries, horizontally ablated cells at the membrane surface to remove the cell body. The microscopic observations and the protein expression studies suggested that the laser treatment caused no apparent damages to pseudopodia. Proteins in whole cells and pseudopodia fractions were individually solubilized, labeled with a highly sensitive fluorescent dye, and separated using two-dimensional difference gel electrophoresis. Among 2508 protein spots observed, 211 had different intensity between whole cells and pseudopodia fractions (more than fourfold differences and $P$-value of $<0.05$ ).

The protein enrichment depended on the pore size. Mass spectrometric protein identification revealed 46 pseudopodia-localizing proteins. The localization of novel pseudopodia-localizing proteins such as RAB1A, HSP90B, TDRD7, and vimentin was confirmed using immunohistochemical examinations. The previous studies demonstrated that these four proteins may function in the cell migration process. This method will provide insights into the molecular details of pseudopodia and a further understanding of malignant phenotypes of tumor cells and novel therapeutic strategies. Laboratory Investigation (2012) 92, 1374-1385; doi:10.1038/labinvest.2012.98; published online 2 July 2012

KEYWORDS: excimer laser ablation; mass spectrometry; proteome; pseudopodia; two-dimensional difference gel electrophoresis

Polarized formation of pseudopodial protrusion during cell migration plays a central role in a variety of physiological and pathological processes, including embryo development, wounding healing, immunity, and cancer metastasis. ${ }^{1,2}$ An in vitro model system was established to recover pseudopodia from cell bodies in order to identify signal pathways and proteins mediating cell migration. ${ }^{3}$ In the model system, cells are plated on a porous membrane and allowed to extend pseudopodia through the pores to the ventral side of the membrane in a chemoattractant-dependent manner. To isolate the pseudopodia, the cell bodies are wiped off from the top of the membrane using a cotton-tipped swab, and proteins are extracted from the resultant membrane. Previously, mass spectrometry-based proteomics combined with this approach were used to identify numerous proteins in pseudopodia protrusions. ${ }^{4-6}$ However, there were critical limitations to the method used in the previous report. Manual separation of pseudopodia from cell bodies created the potential for contamination of cell body components into the pseudopodial extract. Thus, a novel application to purify pseudopodia from cell bodies may provide more precise results. Additionally, the mass spectrometry-based approach described in the previous report did not allow for quantitative comparison between the cell body and pseudopodia, and

\footnotetext{
${ }^{1}$ Department of Pathology, Faculty of Medicine, Kinki University, Osaka, Japan; ${ }^{2}$ Division of Molecular Pathology, Department of Cancer Biology, Institute of Medical Science, University of Tokyo, Tokyo, Japan; ${ }^{3}$ Department of Surgical Oncology, Research Institute for Radiation Biology and Medicine, Hiroshima University, Hiroshima, Japan; ${ }^{4}$ Division of Pharmacoproteomics, National Cancer Center Research Institute, Tokyo, Japan; ${ }^{5}$ Nidek, Gamagori, Aichi, Japan and ${ }^{6}$ Nara Institute of Science and Technology, Ikoma, Nara, Japan

Correspondence: Dr T Kondo, MD, PhD, Division of Pharmacoproteomics, National Cancer Center Research Institute, 5-1-1 Tsukiji, Chuo-ku, Tokyo 104-0045, Japan. E-mail: takondo@ncc.go.jp

${ }^{7}$ These authors contributed equally to this work.
} 
a highly sensitive and quantitative proteomics system is necessary.

We hypothesized that an excimer laser-assisted cell etching technique was a possible remedy for removing cell bodies, avoiding damages on the pseudopodia components. This technique is widely used in clinics as a tool for ophthalmic refractive surgeries such as laser-assisted in situ keratomileusis (LASIK). In LASIK, after the epithelium is flapped from Bowman's layer, the superficial anterior corneal tissue is reshaped by a topographically assisted excimer laser to improve myopia, hypermetropia, and astigmatism. ${ }^{7}$ Because the excimer laser ablates living tissues in a precisely horizontal manner without causing thermal damage to the surrounding area, complications rarely occur. ${ }^{8}$ We hypothesized that by adjusting the laser ablation front to the ventral membrane surface of the cells, the cell body could be ablated while the protrusion in the pores remain intact.

Recent advent proteomics technologies have enabled global protein expression profiling. ${ }^{9}$ Using novel ultrahigh sensitive fluorescent dyes, gel-based protein expression studies have allowed quantitative expression profiling for a small number of cells such as those recovered by laser microdissection. ${ }^{10-13}$ The use of multiple fluorescent dyes with different emission and excitation wavelengths for protein labeling allows inclusion of internal controls in large format gels so that highly reproducible results are expected using two-dimensional difference gel electrophoresis (2D-DIGE). We developed a proteomics system using these methods with a highly sensitive fluorescent dye and a large format gel apparatus. ${ }^{10,11}$ We challenged biomarker development and target discovery using 2D-DIGE. ${ }^{14}$

In this study, we applied a combination of an excimer laser-assisted cell etching technique and 2D-DIGE to characterize proteins in pseudopodia. We identified proteins unique to pseudopodia and confirmed their localization by immunohistochemical examinations.

\section{MATERIALS AND METHODS Cell Culture Conditions}

MDA-MB-231 human breast cancer cells, B16-F10 murine melanoma cells, murine NIH3T3 fibroblast cells, and A549 human lung adenocarcinoma cells were purchased from American Type Culture Collection (ATCC, Rockville, MD, USA). MDA-MB-231 was maintained in L-15 (SigmaAldrich, Gillingham, UK) supplemented with $10 \%$ FBS, 100 units $/ \mathrm{ml}$ penicillin, $100 \mu \mathrm{g} / \mathrm{ml}$ streptomycin (Invitrogen, Carlsbad, CA, USA), and $0.3 \mathrm{~g} / \mathrm{l}$ L-glutamine (SigmaAldrich). B16-F10, NIH3T3, and A549 were grown in Dulbecco's modified Eagle's medium (DMEM) (NakalaiTesque, Kyoto, Japan) supplemented with $100 \mathrm{units} / \mathrm{ml}$ penicillin, $100 \mu \mathrm{g} / \mathrm{ml}$ streptomycin (Invitrogen), 10 and 5\% FBS, respectively. MDA-MB-231 cells were maintained at $37^{\circ} \mathrm{C}$ in air and B16-F10, NIH3T3, and A549 cells were maintained in a $5 \% \mathrm{CO}_{2}$ incubator.

\section{Preparation of Conditioned Medium}

When NIH3T3 cells reached confluence, the medium was replaced with FBS-free DMEM and the cells were maintained for an additional 3 days. Next, the culture medium was filtrated and stored as conditioned medium at $-80^{\circ} \mathrm{C}$.

\section{Cell Culture on Porous Membrane}

Polyethylene terephthalate (PET) membranes (BD, Franklin Lakes, NJ, USA) with pore size of 1 or $3 \mu \mathrm{m}$ were coated with $1 \mu \mathrm{g} / \mathrm{ml}$ fibronectin (Sigma-Aldrich) in Dulbecco's phosphate-buffered saline (D-PBS) ${ }^{15}$ for $30 \mathrm{~min}$. After removing the fibronectin-containing D-PBS, the membrane was bottomed with a 1:1 ratio of culture medium and the above-mentioned NIH3T3-conditioned medium and the culture medium was added to the membrane. ${ }^{6}$ Next, $1 \times 10^{5}$ of MDA-MB-231 cells, $1 \times 10^{4}$ of B16-F10 cells, and $1 \times 10^{5}$ of NIH3T3 cells/well were seeded in 12-well culture plate and cultured on the membrane for 2 days at $37^{\circ} \mathrm{C}$ in a $5 \% \mathrm{CO}_{2}$ incubator.

\section{Microscopic Observations}

After 2 days of culture on the fibronectin-coated porous PET membrane, MDA-MB-231 and B16-F10 cells on the PET membrane were washed with PBS, fixed with $4 \%$ formalin, embedded in paraffin, and cut into sections using an SM2000R (Leica Microsystems, Wetzlar, Germany). Sections were stained using hematoxylin-eosin (HE) and observed using a light microscope (BX51, Olympus, Tokyo, Japan) equipped with a CCD camera DP72 (Olympus).

\section{Excimer Laser Ablation and Protein Extraction}

An MDA-MB-231 cell culture membrane was placed on an irradiation stage of a keratectomy system assisted by an argon fluoride excimer laser $(193 \mathrm{~nm}, 10 \mathrm{~Hz}$; EC-5000 CXIII, Nidek, Gamagori, Japan) adjusted for phototherapeutic keratectomy. ${ }^{16,17}$ Laser scanning was achieved on the membrane substrate by using an image rotator mirror and exposed homogeneously on the area with a diameter of $8 \mathrm{~mm}$. Laser pulse energy was adjusted to be $14 \mathrm{~mJ}$, and 12 pulses were shot per scan. The laser scanning process was monitored using a CCD camera with oblique illumination. Laser scanning was manually continued until disappearing of the light scattering due to the cell bodies. To determine the scanning number, the irradiated cells and membrane were stained using HE after formalin fixation and were observed using a light microscope after mounting to examine whether the cell bodies were completely removed. The cell bodies were perfectly extracted with a scanning number of approximately 20 (range between 18 and 24). We serially processed 100 culture membrane samples. Immediately after each irradiation, the processed area of the membrane was cut using a hollow leather punch with a diameter of $5 \mathrm{~mm}$ and frozen in liquid nitrogen.

Protein extraction was performed from the pool of 100 frozen membranes. Briefly, the membranes were macerated, 
and each protrusion lysate was prepared using lysis buffer containing $50 \mathrm{mM}$ Tris- $\mathrm{HCl} \quad(\mathrm{pH} \quad 7.4), 150 \mathrm{mM} \mathrm{NaCl}$, $1 \%$ Triton X-100, $20 \mathrm{mM}$ EDTA, and a protease inhibitor mixture by rotating at $4{ }^{\circ} \mathrm{C}$. For the whole-cell lysate, 2-day cultures of MDA-MB-231 on the porous membrane were scraped, and the scraped fractions were extracted using lysis buffer. After centrifugation at 13000 r.p.m. for $5 \mathrm{~min}$ at $4{ }^{\circ} \mathrm{C}$ to remove insoluble material, the supernatant was recovered and used in subsequent protein expression studies.

A schematic diagram of laser ablation and protein extraction is provided in Figure 1. The video image of laser ablation is available in Supplementary Video Data.

\section{Immunoblotting and Silver Staining}

Protein lysates from human lung tissues (P1234156 and P1234159) were purchased from BioChain Institute (Hayward, CA, USA). Protein lysates from MDA-MB-231 cells and A549 cells and human lung tissue were suspended in SDS-PAGE sample buffer containing 2\% SDS, $50 \mathrm{mM}$ dithiothreitol, $50 \mathrm{mM}$ Tris, and $10 \%$ glycerol, and incubated at $95^{\circ} \mathrm{C}$ for $5 \mathrm{~min}$. The proteins were fractionated using SDS-PAGE and a $10 \%$ polyacrylamide gel. Fractionated proteins were transferred onto a polyvinyllidene difluoride membrane (Millipore, Bedford, MA, USA), blocked with $5 \%$ skim milk for 30 min, and reacted with an antibody against integrin $\alpha 2$ (2/CD49b, a

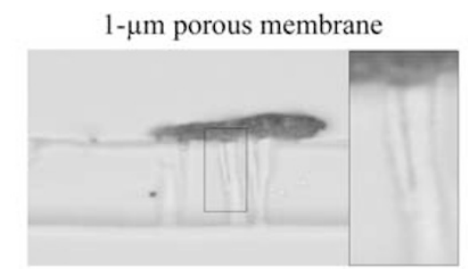

b
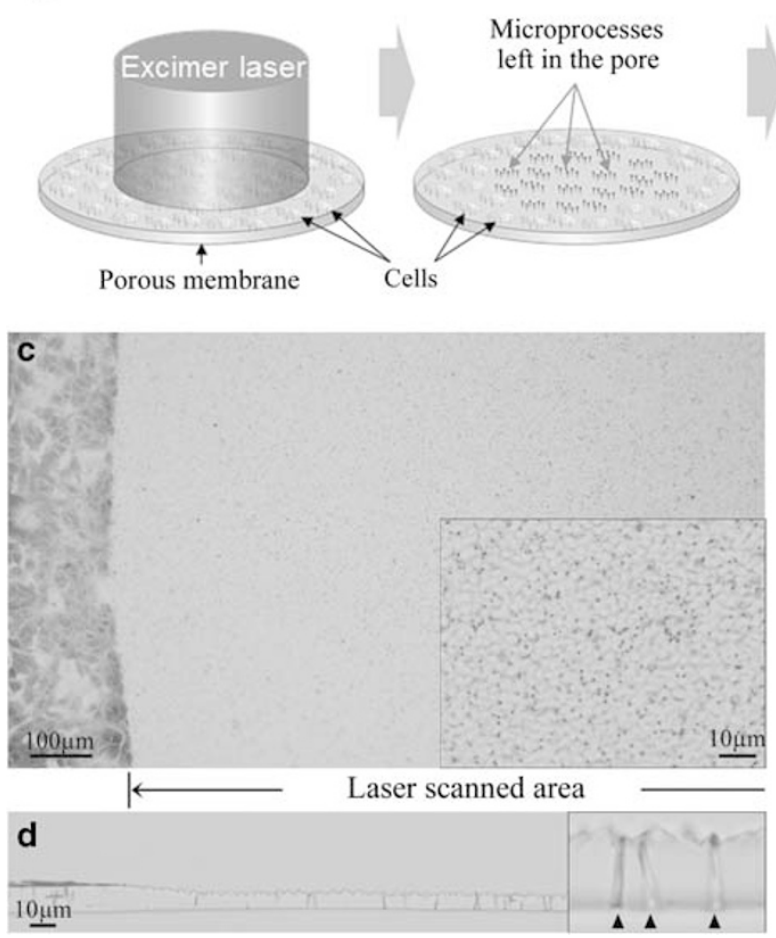

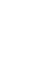

$3-\mu \mathrm{m}$ porous membrane

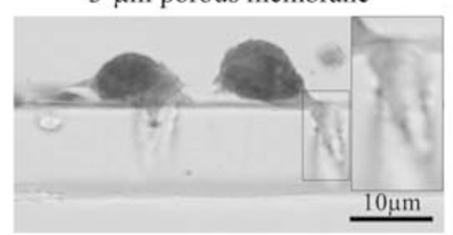

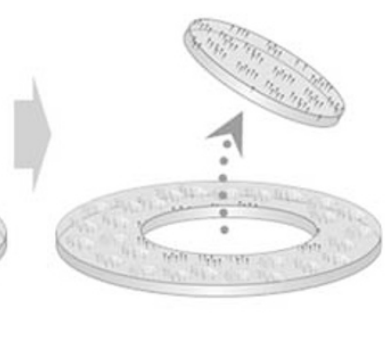

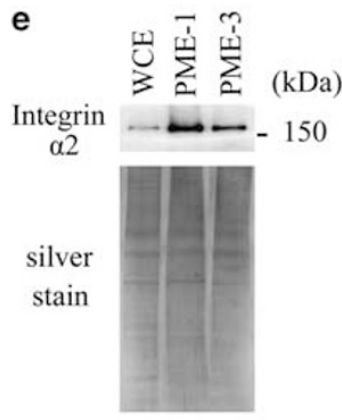

Figure 1 Microscopic observation of pseudopodia in the porous membrane. Pseudopodia in pores with diameters of $1 \mu \mathrm{m}$ (a, left) or $3 \mu \mathrm{m}$ (a, right). Enlarged image in the box shows pseudopodial microprocesses. A schematic diagram of excimer laser ablation is shown. The laser scanning plane was adjusted to the surface of the porous membrane (b, left). The pulse energy and scanning cycles were optimized to completely remove cell bodies and leave the remaining microprocesses intact in the membrane pores (b, middle). Membranes were punched out after ablation and frozen in liquid nitrogen (b, right). The membrane stained with hematoxylin-eosin (HE) was ablated, and no cell bodies remained in the ablated area. The boxed area shows the dot-like appearance of the remaining pseudopodial microprocesses (c). Vertical images of the whole cell and pseudopodia after laser ablation. Arrows in the box indicate pseudopodia of higher magnitude. Enlarged image in the box shows that pseudopodial microprocesses stained with HE remained intact after laser ablation (d). Protein extracts from 1 and $3 \mu \mathrm{m}$ porous membranes were defined as pseudopodial microprocess extracts PME-1 and PME-3, respectively, and the whole-cell extract as WCE. Western blotting revealed highly enriched integrin $\alpha 2$ in PME-1 and PME-3 compared with WCE. A gel prepared in parallel was silver-stained to control for protein loading (e). 
BD, 1:1000 dilution), RAB1A (C-19, Santa Cruz Biotechnology, Santa Cruz, CA, USA, 1:100 dilution), TDRD7 (HPA024529, Sigma-Aldrich, 1:100 dilution), HSP90B (HPA003901, Sigma-Aldrich, 1:100 dilution), and $\beta$-actin (AC-15, Sigma-Aldrich, 1:100 dilution) at $4{ }^{\circ} \mathrm{C}$ overnight. Then, the membranes were incubated with horseradish peroxidase-conjugated secondary anti-mouse antibody (Santa Cruz Biotechnology, 1:1000 dilution) for integrin $\alpha 2$ and $\beta$-actin and anti-rabbit antibody (Santa Cruz Biotechnology) for RAB1A, TDRD7, and HSP90B at $4{ }^{\circ} \mathrm{C}$ for $2 \mathrm{~h}$. Protein complexes were detected using ECL Western Blotting Detection Reagents (GE Healthcare, Uppsala, Sweden). The proteins fractionated by SDS-PAGE in parallel experiments were silver-stained using the Proteo Silver ${ }^{\mathrm{TM}}$ Plus Silver Stain Kit according to the manufacture's instruction (SigmaAldrich).

\section{D-DIGE and Protein Identification by Mass Spectrometry}

Protein expression profiling was achieved using 2D-DIGE with a highly sensitive fluorescent dye and a large format gel, as previously described. ${ }^{10}$ Briefly, the internal control sample was prepared by mixing a portion of all individual samples. Next, $5 \mu \mathrm{g}$ of the internal control sample and individual sample were labeled with Cy3 and Cy5 (CyDye DIGE Fluor saturation dye; GE Healthcare), respectively, according to our previous report. ${ }^{10}$ These differentially labeled protein samples were mixed and separated using 2D-DIGE. The firstdimension separation was achieved using IPG DryStrip gels $(24 \mathrm{~cm}$ in length; pI, 4-7, GE). The second-dimension separation was achieved using SDS-PAGE with a large format gel apparatus $(33 \mathrm{~cm}$ separation distance; Biocraft, Itabashi, Tokyo, Japan). After electrophoresis, the gels were scanned using laser scanners (Typhoon Trio, GE Healthcare) at appropriate wavelengths. The intensity of the Cy5 image was normalized to that of the Cy3 image for all protein spots in the identical gel using the Progenesis SameSpot software (Nonlinear Dynamics, Newcastle upon Tyne, UK). All samples were analyzed in triplicate, and the intensity between the three gels was normalized for statistical analysis. System reproducibility was verified by comparing protein profiles obtained from three independent separations of identical samples.

Proteins corresponding to the protein spots were identified using mass spectrometry according to our previous report. ${ }^{10}$ Briefly, MDA-MB-231 cells were treated with urea lysis buffer $(6 \mathrm{~mol} / \mathrm{l}$ urea, $2 \mathrm{~mol} / \mathrm{l}$ thiourea, 3\% CHAPS, 1\% Triton $\mathrm{X}-100)$, and total cell lysate was recovered after centrifugation. Next, $100 \mu \mathrm{g}$ of protein was separated using twodimensional gel electrophoresis as described above, and target protein spots were recovered as gel plugs by using a protein spot recover machine (Molecular Hunter, AsOne, Osaka, Japan). Proteins in the gel plugs were manually digested using modified trypsin (Promega, Madison, WI, USA), and the trypsin digests were subjected to LC/MS
(Finnigan LTQ linear ion trap mass spectrometer, Thermo Electron, San Jose, CA, USA). The Mascot search (version 2.1; Matrix Science, London, UK) was conducted to identify the mass of the peptide ion peaks compared with the SWISS PROT database (Homo sapiens, 12867 sequences in the Sprot_47.8 FASTA file). Proteins with Mascot scores of $\geq 33$ with at least 2 peptides were considered as positively identified.

\section{Immunostaining and Confocal Microscopy}

A total of $5 \times 10^{4}$ MDA-MB-231 cells were cultured on fibronectin-coated porous membrane for 2 days. The cells were washed 3 times with PBS and fixed with $4 \%$ formalin at room temperature for $15 \mathrm{~min}$. Membranes were washed 3 times with PBS and permeabilized with $0.25 \%$ Triton-X (Sigma-Aldrich) in PBS at room temperature for $5 \mathrm{~min}$. After washing 3 times with PBS, the membranes were incubated in blocking buffer containing 2\% BSA in PBS for $10 \mathrm{~min}$. The cells were treated with antibodies against RAB1A (1:12.5 dilution), TDRD7 (1:50 dilution), HSP90B (1:1000 dilution), and vimentin (1:100 dilution) (RV20, BD) in the blocking buffer for $2 \mathrm{~h}$ at room temperature. Subsequently, the cells were incubated with Alexa Flour 488-conjugated goat antirabbit IgG antibodies (1:100 dilution) (Molecular Probes, Invitrogen) against RAB1A, TDRD7, and HSP90B, and Alexa Flour 488-conjugated goat anti-mouse IgG antibody (Molecular Probes, Invitrogen, 1:100 dilution) against vimentin antibody in the blocking buffer for $1 \mathrm{~h}$ at RT. After washing 3 times with PBS, phalloidin (Sigma-Aldrich) staining was performed for $20 \mathrm{~min}$ at room temperature. Next, the stained cells on the membrane were washed 3 times with PBS, mounted, and covered with glass coverslips. The stained cells were then examined using a NIKON A1 confocal scanning system equipped with 488-nm argon and 568-nm helium-neon lasers (Nikon Corporation, Tokyo, Japan). X-Y$Z$ vertical sections were generated using a $0.5-\mu \mathrm{m}$ motor step. Each image represents double averaged (40- to 50-line scan) images.

\section{Construction of Plasmid Vectors Expressing RAB1A and siRNA against RAB1A}

The cDNA construct for RAB1A inserts was amplified by PCR using KOD FX DNA polymerase (Toyobo, Osaka, Japan) with the following primer set: sense, $5^{\prime}$-CAGTGACA TGTCCAGCATGA-3' (containing the first codon of RAB1A); antisense, 5'-GCAGCTACATACAGTACAATTCAGG-3' (containing the stop codon of RAB1A). The PCR products were resolved by electrophoresis on $1 \%$ agarose gels and stained with ethidium bromide. Targeted bands were excised from gels and DNA was extracted and purified using the Wizard ${ }^{\circledR}$ SV Gel and PCR Clean-Up System (Promega) as described by the manufacturer. Extracted DNA was incubated at $70{ }^{\circ} \mathrm{C}$ with Taq polymerase and adenosine triphosphate for $30 \mathrm{~min}$ and ligated into pTA2 vector (Toyobo). Then, pTA2-RAB1A was enzymatically restricted with BamHI and EcoRV. The 
restricted pTA2-RAB1A was resolved by electrophoresis on $1 \%$ agarose gels and stained with ethidium bromide. Targeted bands were excised from gels and DNA was extracted and purified using the Wizard SV Gel and PCR Clean-Up System. Extracted DNA chains were annealed and ligated into the BamHI/HpaI sites of pCX4-bsr, a modified pCXbsr retroviral vector ${ }^{18}$ provided by Dr T Akagi (Osaka Bioscience Institute, Osaka, Japan), and sequenced. The plasmids were extracted and the accuracy of the constructs was confirmed by sequencing.

The pSilencer4.1-CMVneo siRNA plasmid vector (Ambion, Austin, TX, USA) was used to construct pSilencer4.1CMVneo-si-RAB1A and pSilencer4.1-CMVneo-scramble. A DNA chain with the RAB1A-targetting siRNA sequence or the scrambled fragment one was purchased from Ambion. The RAB1A-targetting sequences were as follows: 5'-GATCCCA ATCACCTCCAGTTATTATTCAAGAGATAATAACTGGAGGT GATTGTT-3' (sense) and 5'-AGCTTAACAATCACCTCCAGT TATTATCTCTTGAATAATAACTGGAGGTGATTGG-3' (antisense). The sequences had no homology with any other predicted protein-coding genes of the human genome according to manufacturer's instruction. The DNA chains were annealed and ligated into the BamHI/HindIII sites of pSilencer4.1-CMVneo to generate pSilencer4.1-CMVneo-si-RAB1A. The negative control pSilencer4.1-CMVneo-scramble vector was constructed in the same manner. The plasmids were extracted and the accuracy of the insert sequence was confirmed by sequencing.

\section{Transfection and Measurement of the Pseudopodial Length}

For overexpression experiments, MDA-MB-231 cells on fibronectin-coated $3 \mu \mathrm{m}$ porous membrane with NIH3T3conditioned medium were transiently transfected with pCX4bsr-RAB1A using FuGENE ${ }^{\circledR} 6$ (Roche Applied Science, Indianapolis, IN, USA). In brief, $2.0 \times 10^{5}$ cells were seeded on $60 \mathrm{~mm}$ culture dishes overnight until $50-80 \%$ confluence was reached. Serum-free medium $(194 \mu \mathrm{l})$ and $6.0 \mu \mathrm{l}$ of FuGENE 6 reagent were mixed in $1.5 \mathrm{ml}$ tubes and incubated for $5 \mathrm{~min}$ at room temperature. Plasmid vectors $(2.0 \mu \mathrm{g}$ each) were added and the contents were mixed and incubated with transfection reagent and DNA complex for at least $15 \mathrm{~min}$ at room temperature. The transfection reagent and DNA complex were added dropwise to the cultured cells and incubated for $48 \mathrm{~h}$. For knockdown experiments, MDA-MB231 cells were transfected transiently with the pSilencer4.1CMVneo-si-RAB1A and scramble-pSilencer4.1-CMVneo vector constructs using Nucleofector with solution $\mathrm{V}$ (Lonza, Basel, Switzerland).

Then, the cells were immunostained with phalloidin and applied to confocal microscopy.

\section{Statistical Analysis}

Data about the length of the pseudopodial microprocesses were analyzed using Student's $t$-test and box plot method. A $P$-value of $\leq 0.05$ was regarded as significant.

\section{RESULTS}

\section{Pseudopodial Microprocesses in Porous Membranes}

MDA-MB-231 breast cancer cells were seeded onto $10 \mu \mathrm{m}$ thick membranes with 1 or $3 \mu \mathrm{m}$ pores. We found that membrane protrusions (eg, pseudopodia) were extended into the membrane pores from the ventral side of the cell body (Figure 1a). Protrusion diameters were $<10 \mathrm{~nm}$ and $1 \mu \mathrm{m}$ in $1-\mu \mathrm{m}$ (Figure 1a, left) and $3-\mu \mathrm{m}$ (Figure 1a, right) porous membranes, respectively. Protrusion lengths varied from 2 to $10 \mu \mathrm{m}$ in both types of porous membranes (Figure 1). Formation of membrane protrusions did not occur in the absence of NIH3T3-conditioned medium, although it was detectable when cells were cultured on $8 \mu \mathrm{m}$ porous membrane (data not shown). Highly invasive melanoma cells, B16-F10 cells, formed similar membrane protrusions in the same tissue culture conditions as MDA-MB-231; however, nontumorigenic cells such as NIH3T3 did not (data not shown).

\section{Isolation of Pseudopodial Microprocesses}

An excimer laser-assisted cell etching technique was used to remove cell bodies from the porous membrane. A schematic diagram of the laser ablation is illustrated in Figure $1 \mathrm{~b}$ and the video image of the laser ablation process is available in Supplementary Video Data. The video image showed that the cell body was removed in a short period. After treatment with an excimer laser-assisted cell etching, the membrane protrusions were observed to be dot-like structures (Figure 1c). Vertical images showed that cell bodies were completely removed and pseudopodia structures remained intact by visual inspection (Figure 1d). We examined the contents of integrin $\alpha 2$ that had accumulated in epithelial cell pseudopodia. ${ }^{19}$ Immunoblotting also revealed that integrin $\alpha 2$ was highly enriched in the pseudopodia fraction compared with the whole cell, regardless of pore diameter, and without degradations (Figure 1e). In addition, enriched localization of integrin $\alpha 2$ was observed in pseudopodia on confocal imaging (Supplementary Figure S1).

\section{Proteins Enriched in Pseudopodial Microprocess Extract} We compared protein content in pseudopodial microprocess extract (PME) and whole-cell extract (WCE) using 2D-DIGE and an internal control sample (Figure 2a). Proteome data resulting from 2D-DIGE included 2508 protein spots (Figure $2 \mathrm{~b}$ and Supplementary Figure S2a). Scatter plot analysis demonstrated that high reproducibility was observed by performing the experiment in triplicate; the intensity of at least $97.2 \%$ protein spots was scattered within twofold differences (Supplementary Figure S2b). When identical samples were independently separated 3 times, the standardized and averaged intensity of at least $97.2 \%$ protein spots scattered within a twofold difference (Supplementary Figure S2b). Thus, the protein spots that met the following criteria were subjected to mass spectrometric protein identification: spots for the $1 \mu \mathrm{m}$ porous membrane group, a false 

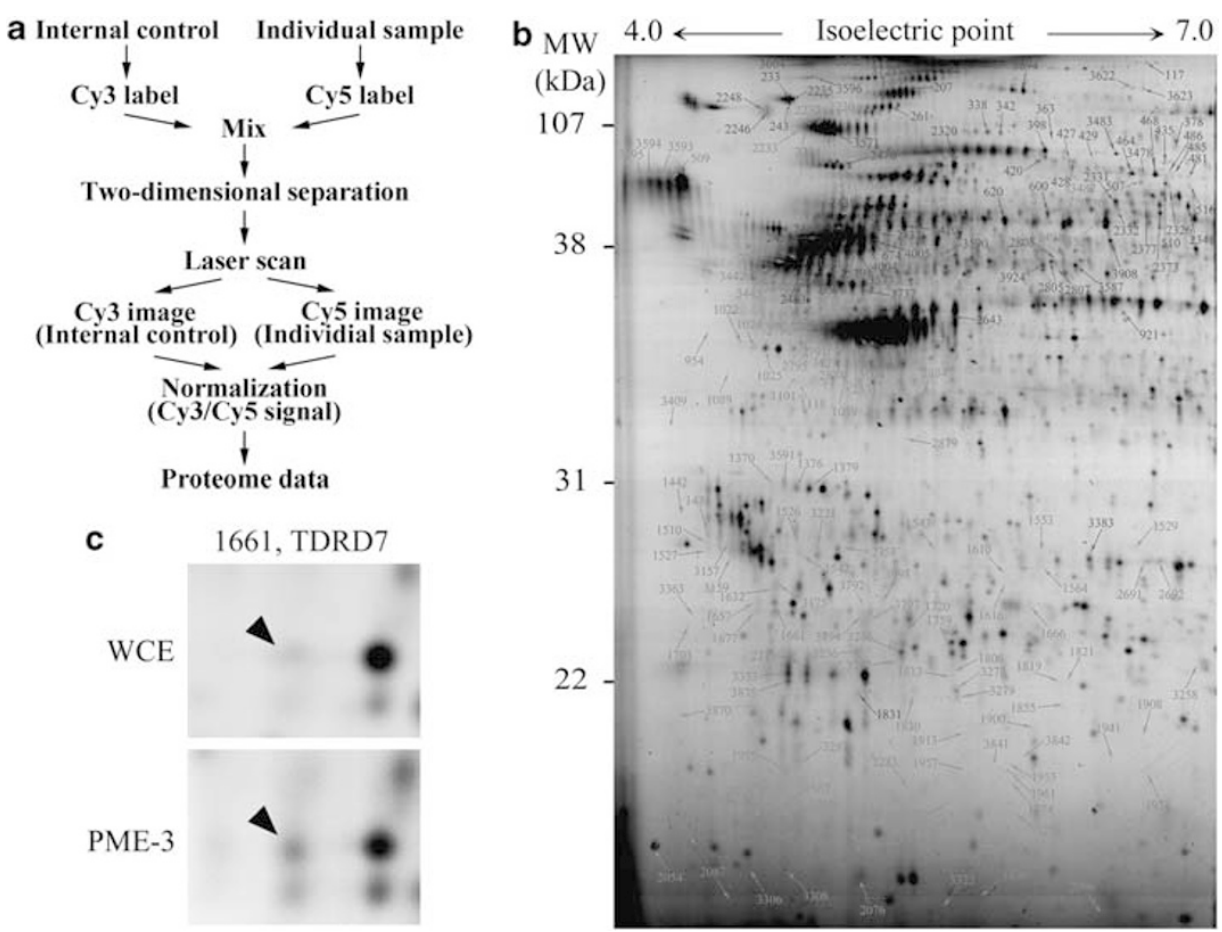

Figure 2 Protein expression profiling by two-dimensional difference gel electrophoresis (2D-DIGE). Schematic diagram of work flow of 2D-DIGE (a). Image of separated proteins on the gel. Enlarged 2D image is shown in Supplementary Figure 1A (b). The location of protein spots for TDRD7 was observed in pseudopodia (upper) and whole-cell (lower) lysates (c).

discovery rate of $<0.001$, and a fold difference of $>6$ between the protrusions and the whole cell group; spots for $3 \mu \mathrm{m}$ pore membrane group, a false discovery rate of $<0.001$, and a fold difference of $>4$ between the protrusions of the $3 \mu \mathrm{m}$ porous membrane group and the whole cell group. According to these criteria, we selected 67 and 132 spots with higher intensity and 29 and 74 spots with lower intensity in PME for the $1 \mu \mathrm{m}$ porous membrane (PME-1) and PME for the $3 \mu \mathrm{m}$ porous membrane (PME-3) than in $\mathrm{WCE}$, respectively (Table 1). Protein identification using liquid chromatography-mass spectrometry/mass spectrometry (LC-MS/ MS) revealed 21 and 45 unique proteins with higher expression in PME-1 and PME-3 than in the WCE, and 19 and 36 proteins with lower expression in PME-1 and PME-3, respectively (Table 1, Supplementary Tables $\mathrm{S} 1-\mathrm{S} 3$; all supportive data for protein identification, including raw data, are available upon request). The representative mass spectrum is shown in Supplementary Figure S3. All but two proteins were commonly enriched or lowered in PME-1 and PME-3. As an example of proteins in the pseudopodia fraction, the localization of TDRD7 (spot number 1661) is demonstrated in Figure 2c.

\section{Subcellular Localization of Identified Proteins}

Localization of the identified proteins was immunohistochemically validated using antibodies against RAB1A,
HSP90B, TDRD7, and vimentin. First, we examined subcellular localization of these proteins in MDA-MB-231 cells without treatment using NIH3T3-conditioned medium. The four proteins showed unique localizations: RAB1A, diffuse pattern in the nucleus and cytoplasm (Figure 3); HSP90B, mesh-like or punctate appearance in the cytoplasm; TDRD7, spotty features in the nucleus; and vimentin, cytoskeletal fibrous structures (Figures 4-6, respectively). Phalloidin staining demonstrated well-developed actin stress fibers across cells. No pseudopodial microprocesses were observed when NIH3T3-conditioned medium was not used. After treatment with NIH3T3-conditioned medium, pseudopodial microprocesses were observed and these proteins localized in pseudopodial microprocesses with actin stress fibers at the cell-membrane interface. Immunohistochemical analysis confirmed a novel localization of RAB1A, HSP90B, TDRD7, and vimentin in pseudopodial microprocesses, which is consistent with the results of 2D-DIGE (Table 1 and Figures 3-6). In addition, endogenous RAB1A, HSP90B, TDRD7, and vimentin expression for naive MDA-MB-231 cells, human lung tissue, and human lung adenocarcinoma A549 cells was validated using western blot (Supplementary Figure S4).

\section{The Length of Pseudopodial Microprocesses}

To validate whether the identified molecules are involved in forming pseudopodial microprocesses, RAB1A over- 
Table 1 Proteins upregulated in pseudopodia microprocesses in 1 or $3 \mu \mathrm{m}$ porous membrane

Accession no. Identified protein ${ }^{a}$

\section{Cytoskeleton (3)}

Actin-associated (2)

$\begin{array}{ll}\text { P60709 } & \text { Actin, cytoplasmic } 1 \\ \text { P04632 } & \text { Calpain small subunit } 1\end{array}$

Intermediate filament (1)

P08670 Vimentin

Chaperones (5)

P08238 Heat shock protein HSP 90- $\beta$

P11142 Heat shock cognate $71 \mathrm{kDa}$ protein

P40227 T-complex protein 1 subunit-æ

Q9UHV9 Prefoldin subunit 2

Translation (2)

P60842 Eukaryotic initiation factor 4A-I

P08865 40S ribosomal protein SA

Q13765 Nascent polypeptide-associated complex subunit- $\alpha$

RNA binding proteins (1)

O00571 ATP-dependent RNA helicase DDX3X

Ub/Proteasome (1)

Q99460 26S proteasome non-ATPase regulatory subunit 1

Signaling (7)

P61981 14-3-3 protein $\gamma$

P52565 Rho GDP-dissociation inhibitor 1

P81605 Dermcidin

Q92734 Protein TFG

Q13795 ADP-ribosylation factor-related protein 1

P01024 Complement C3

P54756 Ephrin type-A receptor 5

Trafficking (4)

P48444 Coatomer subunit $\delta$

P62820 Ras-related protein Rab-1A

P20340 Ras-related protein Rab-6A

Q9BY43 Charged multivesicular body protein $4 a$

Organelles (9)

Endoplasmic reticulum (2)

P11021 78 kDa glucose-regulated protein

Q01105 Protein SET

Nucleus (6)

P45973

Chromobox protein homolog 5

P06748

Nucleophosmin

P60174

Triosephosphate isomerase

Q12905

Interleukin enhancer-binding factor 2

Q9UNZ2

NSFL1 cofactor p47
Table 1 Continued

\begin{tabular}{cl}
\hline Accession no. & Identified protein $^{\text {a }}$ \\
\hline Q99733 & Nucleosome assembly protein 1-like 4 \\
Q56N19 & N-acetyltransferase ESCO2 \\
Q9BS16 & Centromere protein K \\
Others (13) & \\
P08758 & Annexin A5 \\
P02792 & Ferritin light chain \\
Q15181 & Inorganic pyrophosphatase \\
P09211 & Glutathione S-transferase P \\
O95394 & Phosphoacetylglucosamine mutase \\
O75223 & r-Glutamylcyclotransferase \\
P07741 & Adenine phosphoribosyltransferase \\
P50452 & Serpin B8 \\
Q9NS25 & Sperm protein associated with the nucleus on the \\
& X chromosome B/F \\
Q9P1Z9 & Uncharacterized protein KIAA1529 (also known as TDRD7) \\
Q9H0J4 & Glutamine-rich protein 2 \\
Q9NQ48 & Leucine zipper transcription factor-like protein 1 \\
Q8IUR5 & Transmembrane and TPR repeat-containing protein 1 \\
\hline
\end{tabular}

TDRD7, tudor domain containing 7.

The numeric character in the parentheses means the numbers of identified proteins for each group.

${ }^{\mathrm{a}}$ Protein list, supportive information for protein identification, and functional classification are detailed in Supplementary Tables.

expression and knockdown experiments were conducted on MDA-MB-231 cells on the $3 \mu \mathrm{m}$ porous membrane with the conditioned medium followed by western blotting. We subcloned the RAB1A cDNA into the mammalian expression vector, pCX4-bsr and the RAB1A-targetting siRNA into pSilencer4.1-CMVneo. Western blot analyses revealed that MDA-MB-231 cells overexpressed RAB1A when the cells were transfected with RAB1A cDNA plasmid, whereas RAB1A expression was faint with RAB1A-targetting siRNA (Supplementary Figure S5a). Moreover, the longer pseudopodial microprocesses with phalloidin staining were observed in the RAB1A-overexpressed cells and the fewer and shorter microprocesses were in the RAB1A-knockdown cells compared with the nontransfected cells using confocal microscopy (Supplementary Figure S5b and c).

\section{DISCUSSION}

Identification of proteins associated with psuedopodia structure and functions will lead to a further understanding of cell migration. Tumor cell migration is involved in a critical part of invasion and metastasis. Therefore, such proteins for tumor cells can be considered as a candidate of molecular biomarkers and therapeutic targets. We demonstrated that the combined use of the medical laser technology 
- NIH3T3-CM

\section{Cell body mid-plane}
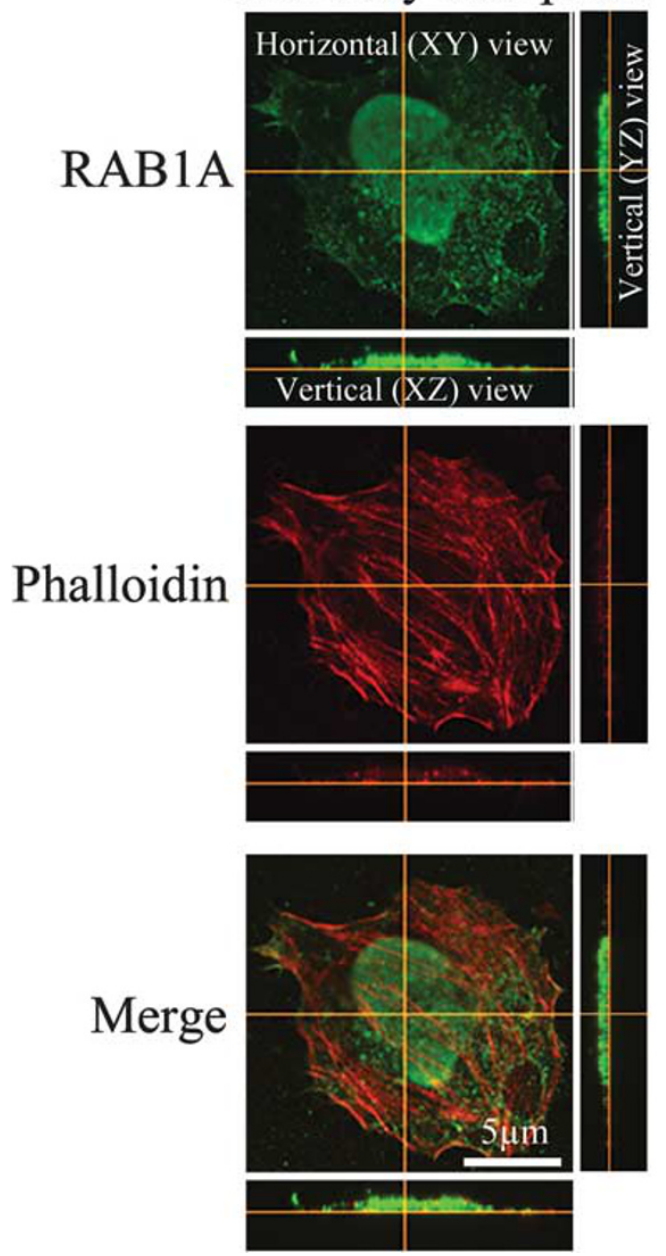

+ NIH3T3-CM
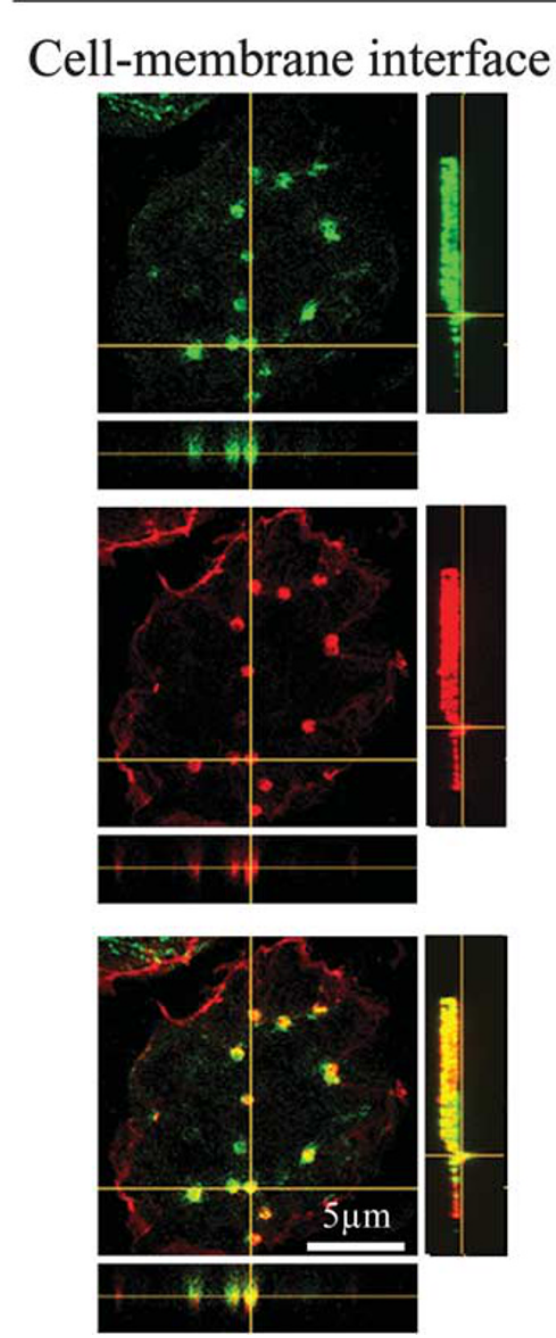
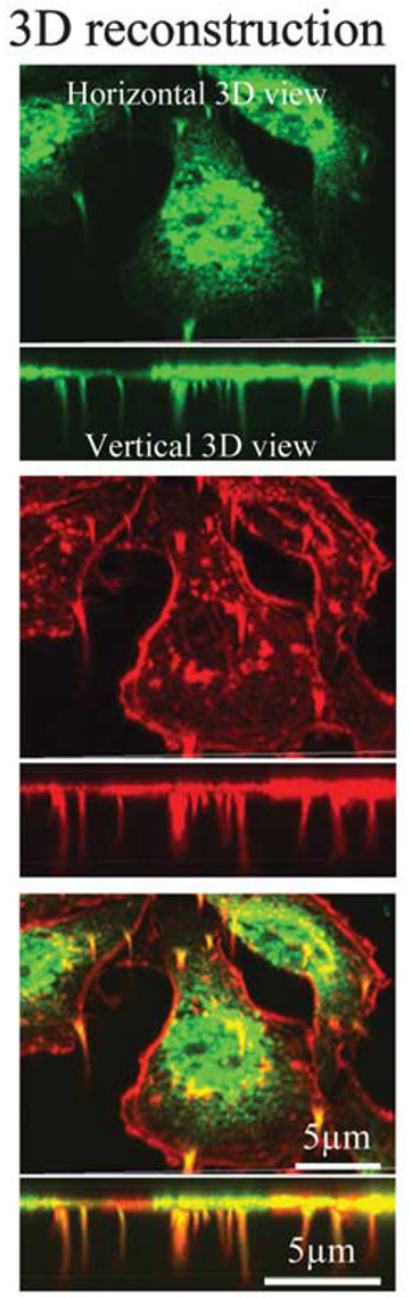

Figure 3 Immunohistochemical view of RAB1A in pseudopodia. Localization of RAB1B before and after treatment with NIH3T3-conditioned medium was determined using immunohistochemical staining. Phalloidin staining was performed to visualize F-actin as a control in pseudopodial microprocesses. Note that RAB1A was observed as a dot-like structure in the horizontal view and as a protrusion in the vertical view following stimulation by $\mathrm{NIH} 3 \mathrm{T3}$-conditioned medium. RAB1A colocalized with F-actin after treatment and was detectable throughout the microprocess.

and the highly sensitive proteomics modalities identified a scarce amount of pseudopodia proteins.

When the cell body was removed by an excimer laserassisted cell etching technique, there was no obvious damage on the pseudopodia appearances (Figure 1c) and the proteins in the pseudopodia remained intact (Figure 1d). This observation is supported by photochemistry and photophysics backgrounds. The laser keratectomy system used in this study was equipped with an argon fluoride excimer laser with a wavelength of $193 \mathrm{~nm}$. Absorption at this wavelength is due primarily to peptide bonds $(\mathrm{O}=\mathrm{CNN})$ in the backbone of proteins in the cell rather than to water. Moreover, the optical absorption depth of the cell at $190 \mathrm{~nm}$ is estimated to be $\sim 500 \mathrm{~nm} .^{20}$ This suggests that protein degradation can be induced only within a depth of $500 \mathrm{~nm}$ from the base of the pseudopodia. Additionally, pore size of the porous membrane ( 1 or $3 \mu \mathrm{m}$ ) is small relative to the excimer laser wavelength, that is, $\leq 15.5$ times as large as the wavelength $(193 \mathrm{~nm})$. This causes the membrane to exhibit a strong light-scattering effect at a wavelength of $193 \mathrm{~nm}$. As a consequence, the excimer laser pulses cannot penetrate into the pores. With these backgrounds and experimental observations, we concluded that the excimer laser ablation did not cause significant protein degradation in the pseudopodia.

Using 2D-DIGE and high sensitive fluorescent dye, we can perform global protein expression studies. Indeed, only a few micrograms of proteins were enough to investigate the psuedopodia-associated proteins in this study. However, 
- NIH3T3-CM

\section{Cell body mid-plane}
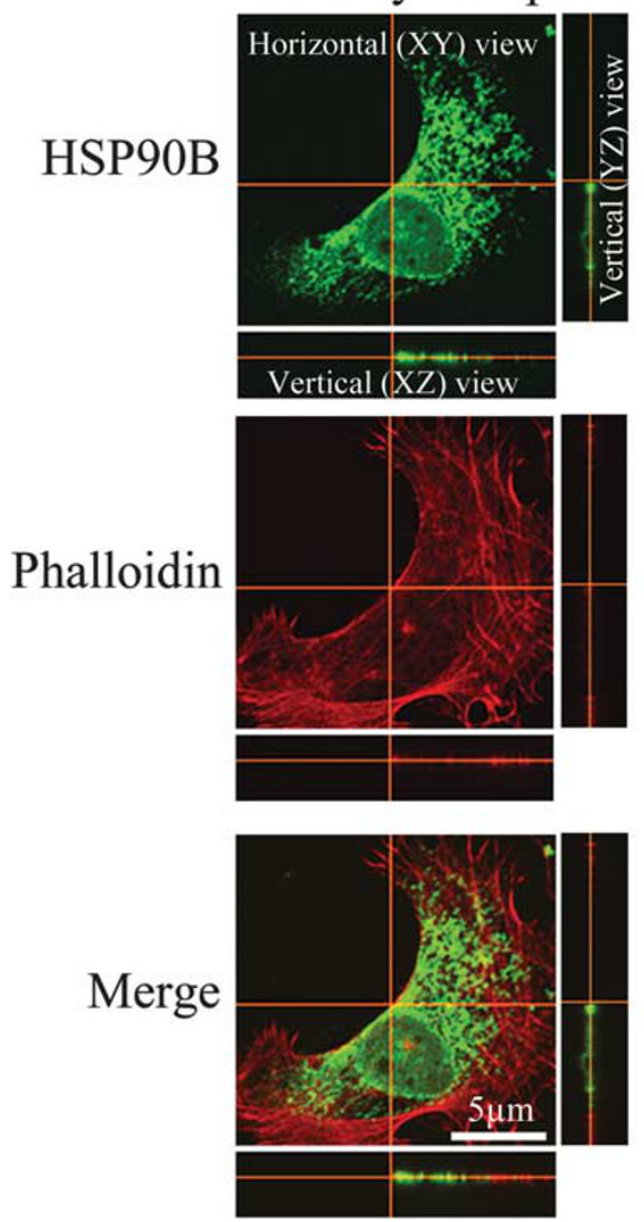

+ NIH3T3-CM
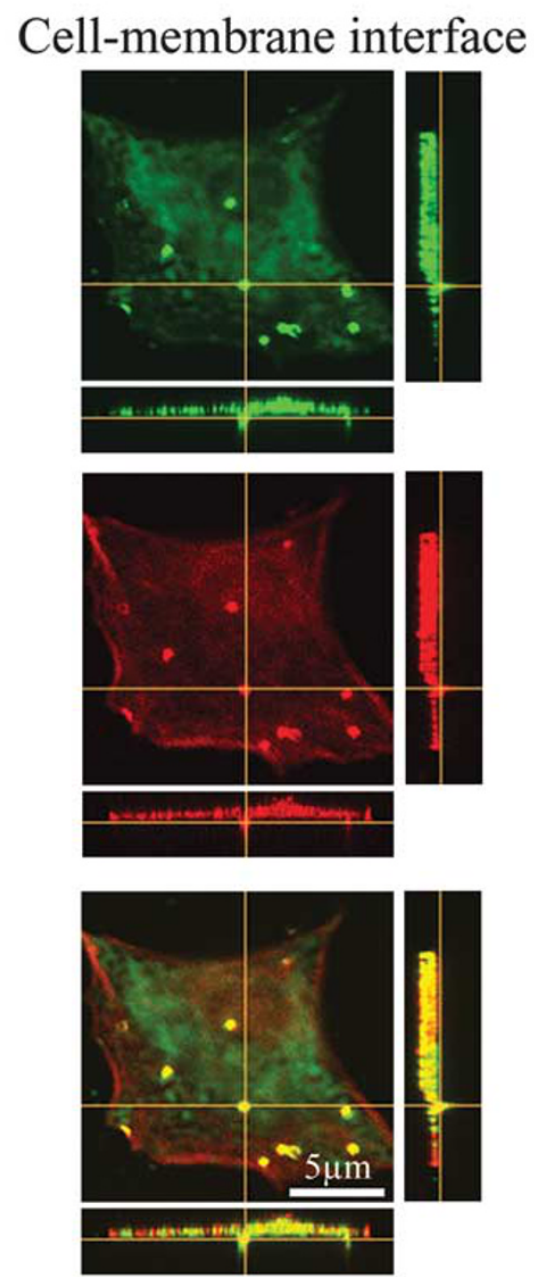
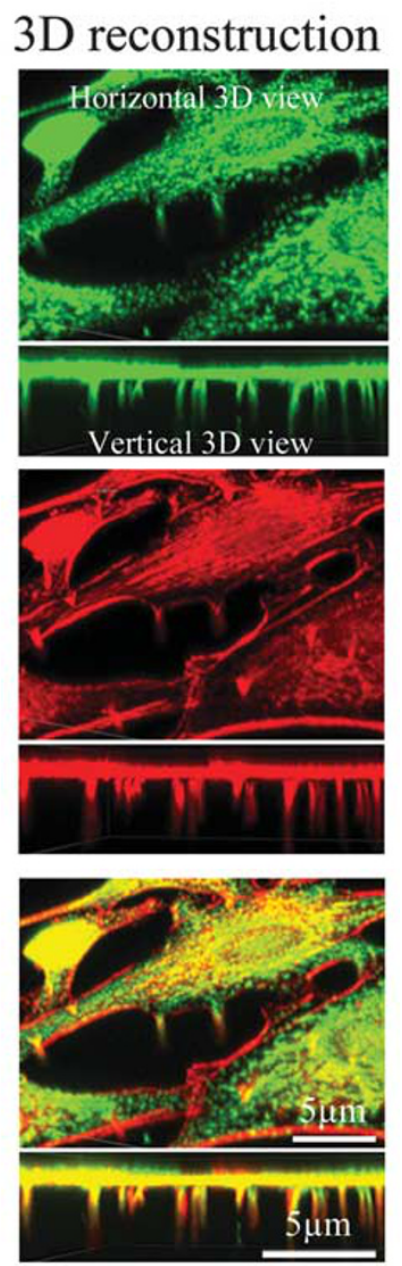

Figure 4 Immunohistochemical view of HSP90B in pseudopodia. Localization of HSP90B without and with treatment with NIH3T3-conditioned medium was determined using immunohistochemical staining. Phalloidin staining was performed to visualize F-actin as a control protein in pseudopodial microprocesses. Note that HSP90B was observed as dot-like structures in the horizontal view and as protrusions in the vertical view after stimulation using NIH3T3-conditioned medium. HSP90B colocalized with F-actin after treatment and was detectable throughout the microprocess.

2D-DIGE allows observation of the proteins with middle to high expression level. This is because of the fact that 2D-DIGE does not select the proteins, and the proteins are detected in the order of expression level. In the case of mass spectrometry-based proteomics, several hundred micrograms of proteins are required for quantitative protein expression profiling, and psuedopodia proteins may not be investigated in a quantitative way. In addition, mass spectrometry also visualizes proteins in the order of expression level, and proteins with low expression may not be observed. Antibodybased proteomics such as antibody array can achieve sensitive and quantitative expression study. We may be able to observe proteins of small amount such as receptors and kinases. However, antibody-based proteomics generally requires much amount of proteins, and cannot be applied for the study of pseudopodia proteins. Taken all together, we concluded that 2D-DIGE is a best method among the proteomics modalities for psuedopodia proteomics.

Among identified proteins, 12 highly expressed proteins in PME molecules, including cytoskeletal and chaperone proteins, were also identified in a past report involving pseudopodial proteomics. ${ }^{4}$ This finding indicated that the present new method certainly examined pseudopodia. On the other hand, pseudopodia in the $1 \mu \mathrm{m}$ pore may morphologically seem to be a part of that in the $3 \mu \mathrm{m}$ pore. This speculation was supported by the observation that most identified molecules in PME-1 were observed in PME-3. The overlapped proteins may be most specific candidate molecules that lead or promote cell migration. On the other hand, several identified proteins, such as TDRD7 and 
- NIH3T3-CM

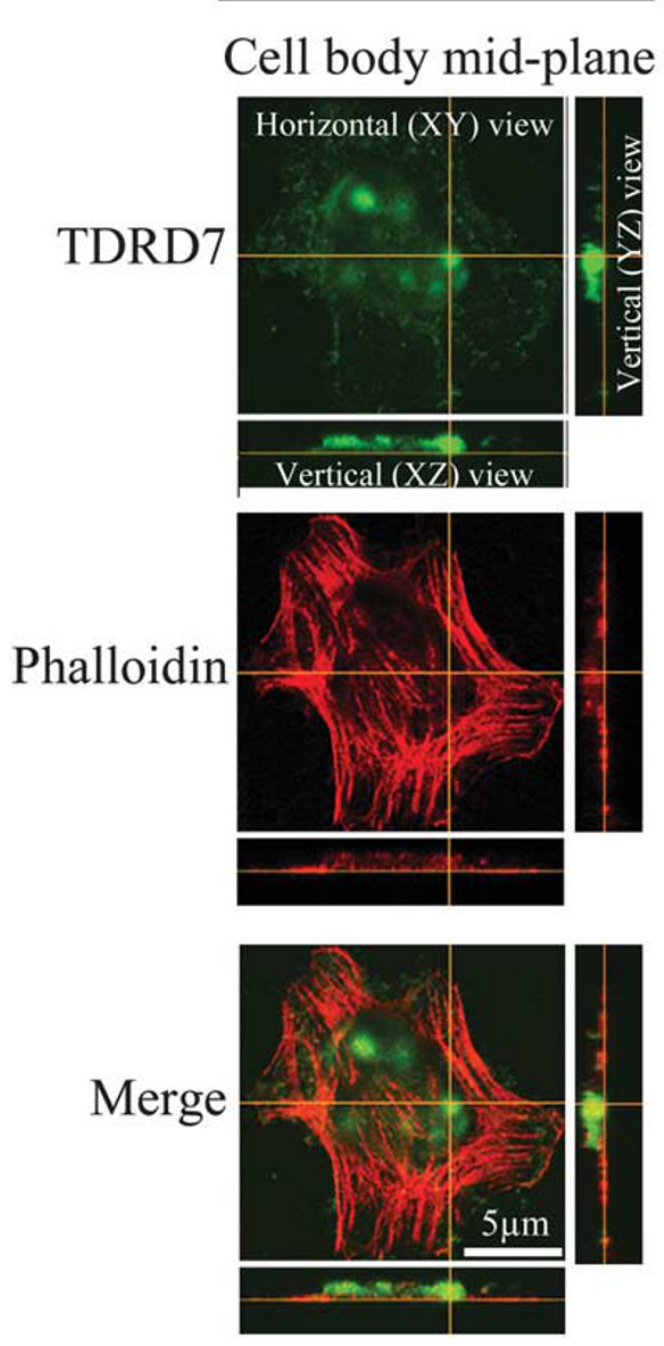

+ NIH3T3-CM
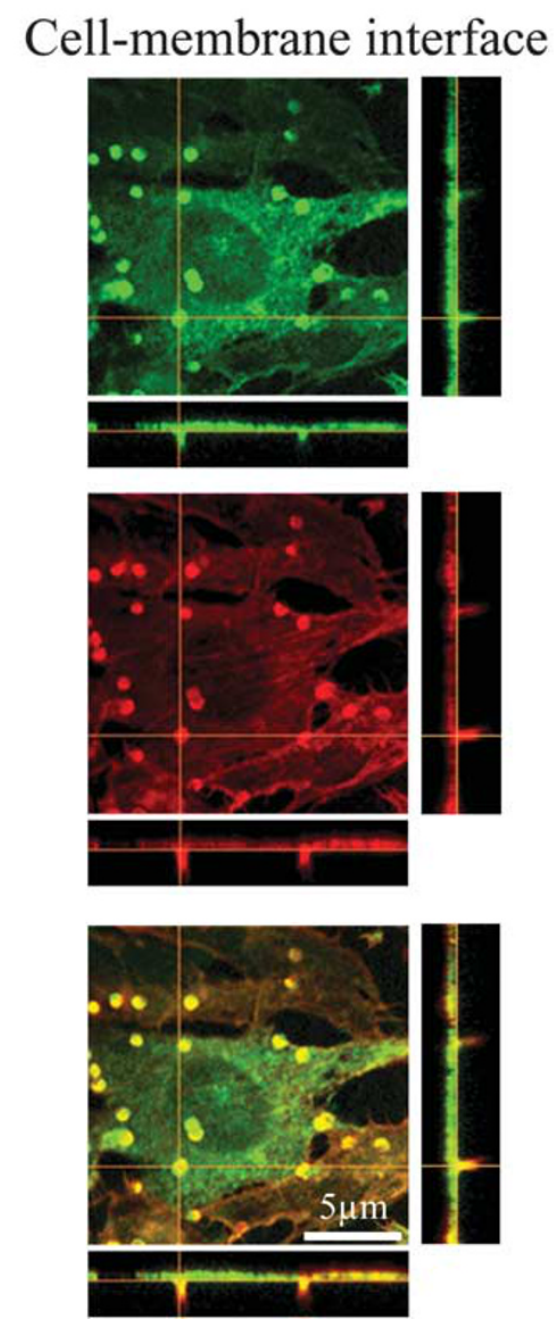

Figure 5 Immunohistochemical view of TDRD7 in pseudopodia. Localization of TDRD7 without and with treatment using NIH3T3-conditioned medium was determined using immunohistochemical staining. Phalloidin staining was performed to visualize F-actin as a control protein in pseudopodial microprocesses. Note that TDRD7 was observed as dot-like structures in the horizontal view and as protrusions in the vertical view after stimulation using NIH3T3-conditioned medium. TDRD7 colocalized with F-actin after treatment and was primarily located in the proximal region of the microprocess.

vimentin, were identified in both 'upregulated proteins' and 'downregulated proteins' in PME compared with WCE. One considerable reason is that specific forms of TDRD7 and vimentin are differently regulated between pseudopodia and cell body. The variations of protein spots may reflect the different posttranslational modifications, and they may play distinct roles in cell behaviors. Further characterization of their posttranslational modifications in relation to psuedopodia should be an interesting subject, although it is not easy because of the sensitivity of mass spectrometry and a lack of methods to control the expression of specific protein forms.

In the present study, the localization of RAB1A, HSP90B, TDRD7, and vimentin in the pseudopodia with actin stress fiber, which is known to be enriched in pseudopodia, ${ }^{1,2}$ was confirmed by immunohistochemical experiment (Figures 3-6). In addition, RAB1A was indicated to play an important role in forming and extending pseudopodial microprocesses in human breast cancer cells by overexpression and knockdown experiments. Previous studies demonstrated that these four proteins may function in the process of cell migration. HSP90B is known to function as a chaperone for proper folding of integrin molecules. ${ }^{21,22}$ Vimentin filaments are shown to be connected to integrin matrix adhesion sites. ${ }^{23}$ Interestingly, guanosine triphosphatase activity of RAB1A and $\mathrm{N}$-terminal phosphorylation of vimentin filaments are involved in vesicle trafficking of integrins to the plasma membrane.$^{24}$ Although the specific function is still unknown, TDRD7 is a scaffold for various proteins including 
- NIH3T3-CM

\section{Cell body mid-plane}
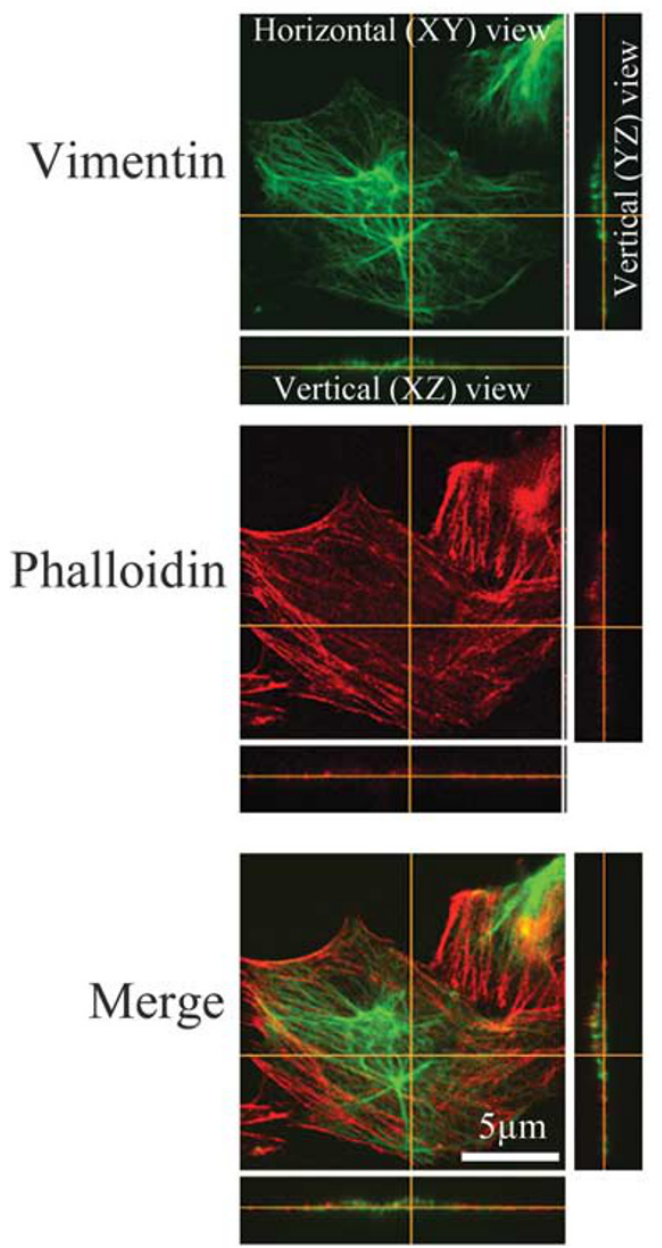

+ NIH3T3-CM
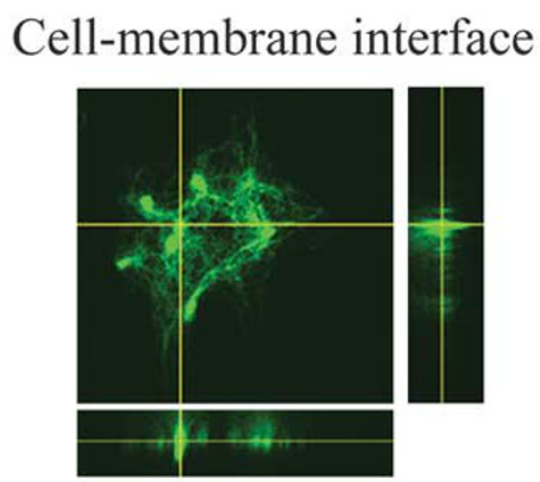

$3 \mathrm{D}$ reconstruction
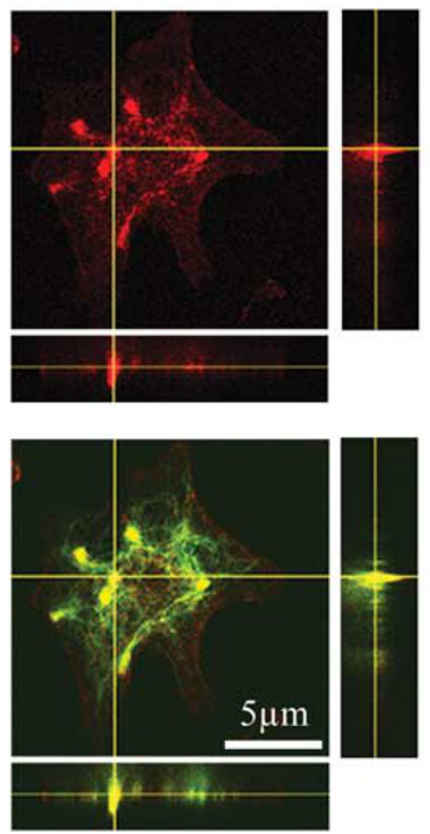
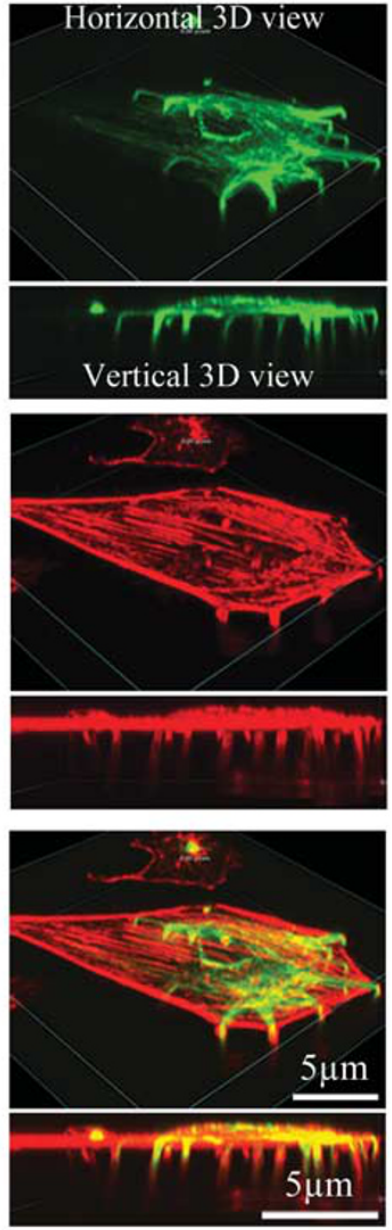

Figure 6 Immunohistochemical view of vimentin in pseudopodia. Localization of vimentin without and with treatment using NIH3T3-conditioned medium was determined using immunohistochemical staining. Phalloidin staining was performed to visualize F-actin as a control protein in pseudopodial microprocesses. Note that vimentin was observed as dot-like structures in the horizontal view and as protrusions in the vertical view after stimulation using $\mathrm{NIH} 3 \mathrm{T3}-\mathrm{conditioned} \mathrm{medium.} \mathrm{Vimentin} \mathrm{colocalized} \mathrm{with} \mathrm{F-actin} \mathrm{after} \mathrm{treatment} \mathrm{and} \mathrm{was} \mathrm{primarily} \mathrm{located} \mathrm{in} \mathrm{the} \mathrm{proximal} \mathrm{region} \mathrm{of} \mathrm{the} \mathrm{microprocess.}$

Ser/Thr kinase PCTAIRE $2^{25}$ and TACC $1 .{ }^{26}$ Thus, these four proteins may participate in integrin-dependent pseudopodia formation and directional cell migration. Their functional role for pseudopodia and possible clinical utilities are worth investigating in further studies.

In conclusion, we established a novel application for pseudopodia proteomics by using a fully developed medical nanodevice and a proteomic modality. Proteomics showed pseudopodia to be dynamic cellular components involved in cytoskeletal remodeling, protein synthesis, trafficking, and degradation as well as involved in various signal transduction pathways. We observed significant proteomic differences between pseudopodia of different diameters and between cell lines with different motile potentials. We confirmed novel pseudopodial localization of RAB1A, HSP90B, TDRD7, and vimentin, which play an important role in cell migration. Additional proteomic studies using varying pore sizes of membranes and different cell types, followed by functional studies of the identified proteins, will reveal the precise molecular basis of cell migration.

Supplementary Information accompanies the paper on the Laboratory Investigation website (http://www.laboratoryinvestigation.org)

\section{ACKNOWLEDGEMENTS}

This work was supported by grants from the Ministry of Education, Culture, Sports, Science and Technology of Japan, from the Nakatani Foundation of Electronic Measuring Technology Advancement, from the Ministry of Health, Labor and Welfare, and from the Program for Promotion of Fundamental Studies in Health Sciences of the Organization for Pharmaceutical Safety and Research of Japan. 


\section{DISCLOSURE/CONFLICT OF INTEREST}

The authors declare no conflict of interest.

1. Lauffenburger DA, Horwitz AF. Cell migration: a physically integrated molecular process. Cell 1996;84:359-369.

2. Parent CA, Devreotes PN. A cell's sense of direction. Science 1999;284: 765-770.

3. Nguyen TN, Wang HJ, Zalzal S, et al. Purification and characterization of beta-actin-rich tumor cell pseudopodia: role of glycolysis. Exp Cell Res 2000;258:171-183.

4. Jia Z, Barbier L, Stuart $\mathrm{H}$, et al. Tumor cell pseudopodial protrusions. Localized signaling domains coordinating cytoskeleton remodeling, cell adhesion, glycolysis, RNA translocation, and protein translation. J Biol Chem 2005;280:30564-30573.

5. Wang Y, Ding SJ, Wang W, et al. Profiling signaling polarity in chemotactic cells. Proc Natl Acad Sci USA 2007;104:8328-8333.

6. Wang Y, Ding SJ, Wang W, et al. Methods for pseudopodia purification and proteomic analysis. Sci STKE 2007;2007:pl4.

7. Reynolds $\mathrm{A}$, Moore JE, Naroo SA, et al. Excimer laser surface ablation a review. Clin Experiment Ophthalmol 2010;38:168-182.

8. Solomon KD, Fernandez de Castro LE, Sandoval HP, et al. LASIK world literature review: quality of life and patient satisfaction. Ophthalmology 2009;116:691-701.

9. Hanash S, Taguchi A. The grand challenge to decipher the cancer proteome. Nat Rev Cancer 2010;10:652-660.

10. Kondo T, Hirohashi S. Application of highly sensitive fluorescent dyes (CyDye DIGE Fluor saturation dyes) to laser microdissection and twodimensional difference gel electrophoresis (2D-DIGE) for cancer proteomics. Nat Protoc 2007;1:2940-2956.

11. Kondo T, Seike M, Mori Y, et al. Application of sensitive fluorescent dyes in linkage of laser microdissection and two-dimensional gel electrophoresis as a cancer proteomic study tool. Proteomics 2003:3:1758-1766.

12. Shaw J, Rowlinson R, Nickson J, et al. Evaluation of saturation labelling two-dimensional difference gel electrophoresis fluorescent dyes. Proteomics 2003;3:1181-1195.

13. Unlu M, Morgan ME, Minden JS. Difference gel electrophoresis: a single gel method for detecting changes in protein extracts. Electrophoresis 1997;18:2071-2077.
14. Kondo T, Hirohashi S. Application of 2D-DIGE in cancer proteomics toward personalized medicine. Methods Mol Biol 2009;577:135-154.

15. Ito A, Kataoka TR, Watanabe M, et al. A truncated isoform of the PP2A B56 subunit promotes cell motility through paxillin phosphorylation. EMBO J 2000;19:562-571.

16. Du CX, Shen Y, Wang Y. Comparison of high order aberration after conventional and customized ablation in myopic LASIK in different eyes of the same patient. J Zhejiang Univ Sci B 2007;8:177-180.

17. Victor $G$, Urbano $A$, Marcal $S$, et al. [First Brazilian refractive surgery survey]. Arq Bras Oftalmol 2005;68:727-733.

18. Akagi T, Murata K, Shishido T, et al. v-Crk activates the phosphoinositide 3-kinase/AKT pathway by utilizing focal adhesion kinase and H-Ras. Mol Cell Biol 2002;22:7015-7023.

19. Kong $T, X u D, Y u W$, et al. $G$ alpha 12 inhibits alpha2 beta1 integrinmediated Madin-Darby canine kidney cell attachment and migration on collagen-I and blocks tubulogenesis. Mol Biol Cell 2009;20: 4596-4610.

20. Vogel A, Venugopalan V. Mechanisms of pulsed laser ablation of biological tissues. Chem Rev 2003;103:577-644.

21. Liu B, Li Z. Endoplasmic reticulum HSP90b1 (gp96, grp94) optimizes B-cell function via chaperoning integrin and TLR but not immunoglobulin. Blood 2008;112:1223-1230.

22. Morales C, Wu S, Yang Y, et al. Drosophila glycoprotein 93 is an ortholog of mammalian heat shock protein gp96 (grp94, HSP90b1 HSPC4) and retains disulfide bond-independent chaperone function for TLRs and integrins. J Immunol 2009:183:5121-5128.

23. Gonzales $M$, Weksler $B$, Tsuruta $D$, et al. Structure and function of a vimentin-associated matrix adhesion in endothelial cells. Mol Biol Cell 2001;12:85-100.

24. Ivaska J, Pallari HM, Nevo J, et al. Novel functions of vimentin in cell adhesion, migration, and signaling. Exp Cell Res 2007;313: 2050-2062.

25. Hirose T, Kawabuchi M, Tamaru T, et al. Identification of tudor repeat associator with PCTAIRE 2 (Trap). A novel protein that interacts with the N-terminal domain of PCTAIRE 2 in rat brain. Eur J Biochem 2000;267:2113-2121.

26. Conte N, Delaval B, Ginestier C, et al. TACC1-chTOG-Aurora A protein complex in breast cancer. Oncogene 2003;22:8102-8116. 